The American Association for Thoracic Surgery is accredited by the Accreditation Council for Continuing Medical Education to provide continuing medical education for physicians.

This activity has been approved for AMA PRA Category 1 Credits $^{\mathrm{TM}}$.

\section{The 91st AATS Annual Meeting}

May 7-11, 2011

Pennsylvania Convention Center

Philadelphia, PA

Target Audience

The AATS Annual Meeting is specifically designed to meet the educational needs of:

- Cardiothoracic Surgeons

- Physicians in related specialties including Cardiothoracic Anesthesia, Cardiology, Pulmonology, Radiology, Gastroenterology, Thoracic Oncology, and Vascular Surgery

- Fellows and Residents in Cardiothoracic and General Surgical training programs

- Nurses, Physician Assistants, Perfusionists, and Allied Health Professionals involved in the care of cardiothoracic surgical patients

- Medical students with an interest in cardiothoracic surgery

\section{AATS Annual Meeting Accreditation}

The American Association for Thoracic Surgery is accredited by the Accreditation Council for Continuing Medical Education to provide continuing medical education for physicians.

This activity has been approved for AMA PRA Category 1 Credit(s) ${ }^{\mathrm{TM}}$.

OPERATING ROOMS OF THE FUTURE: Hybrid Technologies $^{\odot}$

Learn What 21st Century Operating Rooms Offer to the Specialty of Thoracic Surgery

Interactive Exhibits-May 8-10, 2011

Educational Program-May 9, 2011

\section{Program Directors}

Raphael Bueno, MD

Brigham \& Women's Hospital

John Byrne, MD

Vanderbilt Heart \& Vascular Institute

Building on the tremendous success of the Operating Rooms of the Future: Hybrid Technologies ${ }^{\circledR}$ exhibits and the Building the Hybrid Operating Room of the Future $^{\odot}$ course held in Toronto, AATS members will once again be able to experience what the 21 st century has to offer for thoracic surgery in Philadelphia in 2011.

The 2011 Operating Room of the Future displays and course program will prepare the surgical community to take the lead in the design, selection, and implementation of the surgical environment in their hospitals.

The 2011 AATS Annual Meeting will once again showcase two multi-purpose interventional operating room suites that integrate digital imaging diagnostics, radiological, catheterization, and surgical capabilities. The two Operating Rooms of the Future: Hybrid Technologies ${ }^{\odot}$ will be constructed on the exhibit floor.

Hybrid operating rooms allow surgeons and their colleagues to perform combined open, minimally invasive, imageguided, and/or catheter-based procedures in the same OR in the same operative setting. These interdisciplinary, multifunctional rooms bring technology to the patient with the goals of maximizing patient care, improving overall outcomes, and decreasing time in the hospital. According to Raphael Bueno, MD, Associate Chief, Division of Thoracic Surgery, Brigham \& Women's Hospital, Boston, "it is expected that the juxtaposition of technologies will allow for innovation in surgical approaches and procedures unimaginable till now."

"The hybrid OR is not just the combination of equipment and technology into one procedural suite, but rather it is the embodiment of a collaborative working environment. This environment fosters the ability to think of new ways to care for patients requiring complex procedures," said John Byrne, MD, Chair, Cardiac Surgery Department, Vanderbilt Heart Institute, Nashville.

Siemens, Philips, and others will collaborate with AATS to construct the Operating Rooms of the Future ${ }^{\odot}$ in the Pennsylvania Convention Center during the AATS Annual Meeting. The equipment on display will be fully operational and fully integrated to give attendees a true life view of the functionality of a hybrid operating room.

EDUCATIONAL PROGRAM: Building a Hybrid OR of the Future ${ }^{\odot}$

Monday, May 9, 2011

1:00 PM-5:30 PM

As an adjunct to the hybrid operating room displays in the exhibit hall, the Building the Hybrid Operating Rooms of the Future ${ }^{\odot}$ course program will give attendees thinking about building a hybrid OR in their hospitals real life 
examples of what works and what doesn't. The program will provide attendees with a real "nuts" and "bolts" discussion of what they need to do to get their projects off the ground.

This program will detail what a hybrid operating room is; what it can accomplish for the hospital, medical personnel, and patients; and will also provide a road map on how to install such an operating room at a hospital.

Target Audience:

- Hospital C-Suite Executives (CEO, CFO, COO, CMO)

- Thoracic Surgeon Leaders

- Directors of Surgery

- Directors of Operating Room

- Directors of Materials Management/Purchasing

- Facility Managers

- Nursing Leadership

Topics Covered:

- How To Convince Your Hospital Administrators to Fund a Hybrid OR

- How to Put the Team Together (Team Composition)

- Where Does the Hybrid OR Fit in a World of ValueBased Reimbursement?

- Building the CT ICU of the Future

ICU of the FUTURE

Interactive Exhibit

May 8-10, 2011

\section{Program Directors}

Robert N. Sladen, MD

Columbia University

Neil A. Halpern, MD

Memorial Sloan-Kettering Cancer Center

New for 2011, AATS members will be able to see firsthand what the future holds for cardiothoracic surgical critical care at the ICU of the Future display.

Located on the exhibit floor between the Cardiac and the General Thoracic Operating Rooms of the Future, the CT ICU of the Future will showcase cutting-edge equipment and the latest technological advances in imaging, advanced information technology, and critical care medicine used in cardiothoracic surgical critical care. In addition to stateof-the-art instruments for monitoring, treatment, and patient care, the display will also feature everything from smart beds and smart glass (used for patient privacy), to the latest in wireless technology, to innovations in ICU design and layout.
To register and reserve housing for the Annual Meeting or for additional information please visit www.aats.org or contact:

\section{American Association for Thoracic Surgery}

900 Cummings Center

Suite 221-U, Beverly, MA, USA 01915

Telephone: +1 (978) 927-8330

Fax: + 1 (978) 524-8890

E-mail: meetings@aats.org

\section{AATS Meetings and Sponsored Events www.aats.org}

February 10-13, 2011

11th Annual International Symposium on Congenital Heart Disease*

Renaissance Vinoy Resort

St. Petersburg, Florida

March 3, 2011

In Vivo Animal Models Course

Bethesda, Maryland

March 4, 2011

Grant Writing Workshop

Bethesda Marriott

Bethesda, Maryland

May 5-6, 2011

Mitral Conclave

Sheraton New York Hotel and Towers

New York, New York

May 7-11, 2011

AATS 91st Annual Meeting

Pennsylvania Convention Center

Philadelphia, Pennsylvania

May 26, 2011

AATS/ASCVTS Postgraduate Course*

Hilton Phuket Arcadia Resort \& Spa

Phuket, Thailand

September 8-10, 2011

International Society for Rotary Blood Pumps Annual Meeting*

Marriott Downtown

Louisville, Kentucky

October 20-21, 2011

7th Triennial Brigham Cardiac Valve Symposium*

Fairmont Copley Plaza Hotel

Boston, Massachusetts

*Co-sponsored by AATS 